\title{
Perinatal undernutrition programmes thyroid function in the adult rat offspring
}

\author{
Rosario Ayala-Moreno ${ }^{1,2}$, Radu Racotta ${ }^{1}$, Brenda Anguiano ${ }^{3}$, Carmen Aceves ${ }^{3}$ and Lucía Quevedo ${ }^{1 *}$ \\ ${ }^{1}$ Departamento de Fisiología "Dr Mauricio Russek", Escuela Nacional de Ciencias Biológicas, Instituto Politécnico Nacional, \\ Carpio y Plan de Ayala, México City, Mexico \\ ${ }^{2}$ Grupo de Investigación en Alimentos y Salud, Facultad de Ciencias Químicas, Universidad La Salle, México City, Mexico \\ ${ }^{3}$ Instituto de Neurobiología, Universidad Nacional Autónoma de México, Campus Juriquilla, Querétaro, Mexico \\ (Submitted 2 November 2012 - Final revision received 30 April 2013 - Accepted 1 May 2013 - First published online 26 June 2013)
}

\section{Abstract}

Increasing evidence suggests that alterations in early nutrition programme physiological changes in adulthood. In the present study, we determined the effects of undernutrition during gestation and lactation on the programming of thyroid function in adult rat offspring. Perinatal undernutrition was achieved by a $40 \%$ food restriction in female Wistar rats from the mating day to weaning. On postpartum day 21 , the offspring of the control and food-restricted dams were weaned and given free access to a commercial diet until adulthood. The results showed that undernourished rats exhibited decreased 3,5, $3^{\prime}$-triiodothyronine $\left(\mathrm{T}_{3}\right.$ ) levels but had normal thyroxine ( $\left.\mathrm{T}_{4}\right)$ and thyrotropin (TSH) levels at weaning; on day 90, these rats displayed a significant flip, exhibiting normalised $\mathrm{T}_{3}$ (total and free) and total $\mathrm{T}_{4}$ levels, but low free $\mathrm{T}_{4}$ and persistently higher TSH levels, which were maintained even on postnatal day 140. This profile was accompanied by a scarce fat depot, a lower RMR and an exacerbated sympathetic brown adipose tissue (BAT) tone (deiodinase type 2 expression) in basal conditions. Moreover, when a functional challenge (cold exposure) was applied, the restricted group exhibited partial changes in TSH (29v. 100\%) and $\mathrm{T}_{4}$ (non-response $v .17 \%$ ) levels, a significant decrease in leptin levels (75 v. 32\%) and the maintenance of a sympathetic BAT over-response (higher noradrenaline levels) in comparison with the control group. The findings of the present study suggest that undernutrition during the perinatal period produces permanent changes in the hypothalamus-pituitary-thyroid axis with consequent low body weight and decreased RMR and facultative thermogenesis. We hypothesise that these changes predispose individuals to exhibiting adult subclinical hypothyroidism.

\section{Key words: Undernutrition: Resting energy expenditure: Thyroid hormones: Facultative thermogenesis: Hypothyroidism}

In humans, undernutritional exposure in fetal and/or neonatal life is associated with an increased risk of adult diseases such as obesity, non-insulin-dependent diabetes and hyperten$\operatorname{sion}^{(1-3)}$. It has been suggested that low substrate availability during these critical periods of development represents a structural stressor producing long-term changes in different tissues. The capacity of the developing tissues to adapt to undernutrition causing permanent alterations has been termed 'metabolic programming'(4,5). Several studies have reported that undernutrition during gestation alters both maternal and fetal levels of messengers such as insulin-like growth factors, growth hormone, insulin, glucocorticoids, leptin, catecholamines, thyroid hormones (TH) and placental hormones, all of which are closely associated with fetal growth and development ${ }^{(6)}$. In rats, the complete functionality of the hypothalamic-pituitary-thyroid (HPT) axis occurs mainly after birth. On the other hand, the thyroid gland begins to differentiate from fetal days 17-18 onwards when the colloid and follicular structures appear, and it reaches its full-grown structure and function on day 10 of lactation ${ }^{(7,8)}$. In this way, the critical period for the development and functional differentiation of the thyroid axis includes both pre- and post-perinatal periods. Extensive literature has demonstrated the crucial role of $\mathrm{TH}$ in the development and function of several tissues, besides in those of the brain. In metabolic terms, TH are crucial for maintaining the RMR and obligatory thermogenesis; they also play an important role in facultative thermogenesis, exerting a synergic effect with catecholamines in brown adipose tissue (BAT) by promoting heat production to maintain body temperature in a cold environment ${ }^{(9)}$ and body weight during overfeeding ${ }^{(10)}$. In the last few years, several studies have shown that nutritional conditions can determine thyroid status in humans ${ }^{(11)}$ and animals ${ }^{(12)}$. In adults, severe food restriction suppresses the activity of the

Abbreviations: BAT, brown adipose tissue; Dio2, type 2 deiodinase; HD1, hepatic 5'-deiodinase; HPT, hypothalamic-pituitary-thyroid; NA, noradrenaline; $\mathrm{T}_{3}, 3,5,3^{\prime}$-triiodothyronine; $\mathrm{T}_{4}$, thyroxine; TH, thyroid hormone; TRH, thyrotropin-releasing hormone; TSH, thyrotropin; TSHR, thyrotropin receptor.

*Corresponding author: L. Quevedo, fax +52 55 57296000/52412, email quevedocorona@hotmail.com 
HPT axis, decreasing pituitary thyrotropin (TSH) content and plasma 3,5, $3^{\prime}$-triiodothyronine $\left(\mathrm{T}_{3}\right)$ and thyroxine $\left(\mathrm{T}_{4}\right)$ levels ${ }^{(13)}$. In the perinatal period, modifications in thyroid status may depend on the period (prenatal or postnatal) and the time when the analysis is carried out, i.e. immediately after food restriction (weaning time) or in adulthood. In general terms, it is known that pups of food-restricted rat dams during gestation, lactation or both exhibit low plasma TSH, $\mathrm{T}_{3}$ and $\mathrm{T}_{4}$ levels at weaning ${ }^{(14-16)}$, but if the analysis is carried out in the post-weaned period or adulthood, rats whose dams were fed protein-deficient diets during the neonatal period consistently exhibit alterations in the thyroid profile such as elevated or normal $\mathrm{T}_{3}$ levels, elevated TSH levels and/or a poor response of pituitary TSH release to in vitro thyrotropin-releasing hormone $(\mathrm{TRH})^{(17-19)}$. In humans, it is difficult to establish nutritional conditions during pregnancy, though low birth weight and small body size at birth are the markers of fetal nutritional deficiencies. These factors have been reported to be associated with an increased risk for developing thyroid dysfunction in adulthood ${ }^{(20,21)}$. The aim of the present study was to analyse the functionality of the HPT axis in the adult offspring of undernourished rat dams during gestation and lactation, in resting conditions and in response to a functional challenge (cold exposure). The present results showed that undernourished rats exhibited transitional changes in thyroid function on postnatal day 21, manifested as decreased $\mathrm{T}_{3}$ levels and normal $\mathrm{T}_{4}$ and $\mathrm{TSH}$ levels, but displayed a significant flip on day 90 , which consisted of normalised $\mathrm{T}_{3}$ (total and free) and total $\mathrm{T}_{4}$ levels, but lower free $\mathrm{T}_{4}$ and persistently higher TSH levels, which were maintained even on postnatal day 140 . This profile was accompanied by a scarce fat depot, a lower RMR and an exacerbated sympathetic BAT tone in basal conditions and attenuated thyroid axis responses to cold exposure, suggesting permanent alterations in both thyroid function and HPT axis.

\section{Materials and methods}

\section{Induction of undernourishment during gestation and} lactation

Female Wistar rats initially weighing 240 (SEM 20) g were housed in individual cages in a room under regulated temperature $\left(22 \pm 2^{\circ} \mathrm{C}\right)$ and $12 \mathrm{~h}$ dark-12 h light cycles. After 2 weeks of adaptation, the rats were randomly assigned to consume a commercial diet (Rodent Laboratory Diet 5001 containing $1 \mu \mathrm{g}$ iodine $/ g$, which ensures the recommended iodine daily intake in both the groups ${ }^{(22)}$ ) and water ad libitum (control group) or a diet representing only $60 \%$ of the mean food intake of the control group (restricted group). All rats were mated with male Wistar rats, and the food regimen was started on this day and continued during gestation and lactation. The experiment was carried out using ten control dams and twelve restricted dams. On partum day, considered as the first lactation day, only eight pups (four females and four males) were retained per dam. After weaning on the 21st day of age, the offspring of the control and restricted dams were housed in individual cages under conditions that were the same as those described above and allowed ad libitum access to water and the commercial diet. Body weight, body length and food intake $(24 \mathrm{~h})$ were measured three times per week until $90 \mathrm{~d}$ of age. On postnatal days 21 and 90, blood samples from the tail tip of female pups were collected and centrifuged at $5000 \mathrm{rpm}$ for $10 \mathrm{~min}$ to obtain plasma, and the plasma was stored at $-20^{\circ} \mathrm{C}$ until TSH and TH (total and free $\mathrm{T}_{3}$ and $\mathrm{T}_{4}$ ) analyses. At $90 \mathrm{~d}$ of age, after measuring the RMR, the female offspring of the control dams and restricted dams were euthanised ( $40 \mathrm{mg} / \mathrm{kg}$ pentobarbital, intraperitoneally), and the carcasses and livers were processed for biochemical analysis. Handling and euthanasia of the rats were reviewed and approved by the ad hoc ethics committees of UNAM and IPN and complied with the Guide for the Care and Use of Laboratory Animals of the Mexican Council for Animal Care (NOM062-ZOO-1999) and International Committee guidelines.

\section{Determination of carcass contents}

The carcasses were obtained by discarding heads, limbs, tails, skins and viscera of the rats and stored at $-20^{\circ} \mathrm{C}$ until the analysis of their components. Protein content was determined using Kjeldahl's method with automatic digestion (Kjeltec auto sampler system 1035, Analyzer Tekator; Foss Tecator, Foss North America Inc.); lipid content was measured using a dried powder of the samples with a Soxhlet apparatus by extraction with petroleum diethyl ether. Retroperitoneal adipose depot was extracted and weighed.

\section{Determination of $R M R$}

The RMR of the offspring was determined using an Oxymax System (Columbus Instruments) with connected Opto-Varimex Mini Devices for estimating motor activity. The rats were fasted overnight for $15 \mathrm{~h}$. In each recording, $3 \mathrm{~min}$ events were measured for $6 \mathrm{~h}$, and the data of $\mathrm{V}_{\mathrm{O} 2}$ (litres $/ \mathrm{kg}^{0.75} \times \mathrm{h}$ ), $\mathrm{CO}_{2}$ production (litres $/ \mathrm{kg}^{0.75} \times \mathrm{h}$ ), resulting respiratory quotient and metabolic rate $\left(\mathrm{kJ} / \mathrm{kg}^{0.75} \times \mathrm{h}\right)$ were entered into a computer, which also recorded activity given as the number of pulses. For more details, see Ayala et al. ${ }^{(23)}$.

\section{Determination of hormone concentrations}

The circulating levels of leptin were measured using a specific ELISA (Millipore Corporation). TSH levels were measured using RIA (Biotrack assay; Amersham Corporation). Total $\mathrm{T}_{3}$ and $\mathrm{T}_{4}$ levels were measured using a homologous RIA standardised in our laboratory ${ }^{(24)}$, and free $\mathrm{T}_{3}$ and $\mathrm{T}_{4}$ levels were measured using ELISA (Diagnostica Internacional).

\section{Determination of cold exposure responses of adult rat offspring of the control dams and restricted dams}

On postnatal day 140 , the male rats were exposed to room $\left(22 \pm 1^{\circ} \mathrm{C}\right)$ or low $\left(4 \pm 1^{\circ} \mathrm{C}\right)$ temperature for $24 \mathrm{~h}$. Blood samples were collected before and after cold exposure and plasma leptin, TSH, $\mathrm{T}_{4}$ and $\mathrm{T}_{3}$ levels were measured. The rats were euthanised, and their tissues (ventral lobe of the liver and interscapular BAT) were dissected, weighed 
and stored at $-70^{\circ} \mathrm{C}$. Hepatic $5^{\prime}$-deiodinase (HD1) activity was measured using the radioiodide release method ${ }^{(25)}$. BAT weight, catecholamine content and type 2 deiodinase (Dio2) mRNA expression were determined in the BAT as indicators of sympathetic response.

\section{Determination of hepatic 5'-deiodinase activity}

Liver samples were homogenised at $1: 10(\mathrm{w} / \mathrm{v})$ in a buffer ( $\mathrm{pH} 7 \cdot 0$ ) containing $10 \mathrm{~mm}$-HEPES, $0.32 \mathrm{M}$-sucrose, $5 \mathrm{~mm}-$ dithiothreitol and $1.0 \mathrm{~mm}$-EDTA. Crude homogenates were centrifuged at $12000 \mathrm{rpm}$ for $2 \mathrm{~min} .{ }^{125}$ I-labelled reverse $\mathrm{T}_{3}$ was purified by passage through a column (Sep-Pak, C-18 Cartridges; Millipore Waters). In the standard assay, $50 \mu \mathrm{l}$ of the homogenate $(5 \mu \mathrm{g}$ of protein) and $50 \mu \mathrm{l}$ of a radiolabelled mix ( $2 \mathrm{~nm}^{-125}$ I-labelled reverse $\mathrm{T}_{3}, 0.5 \mu \mathrm{m}$-non-radiolabelled reverse $\mathrm{T}_{3}$ and $5 \mathrm{~mm}$-dithiothreitol) in a final volume of $100 \mu \mathrm{l}$ were used. After incubation $\left(1 \mathrm{~h}\right.$ at $\left.37^{\circ} \mathrm{C}\right)$, the released acid-soluble ${ }^{125}$ I was isolated by chromatography on Dowex $50 \mathrm{~W}-\mathrm{X} 2$ columns (Bio-Rad) and measured using a gamma counter. Protein content was measured using the Bradford method (Bio-Rad). Results are given as nmol I released/mg protein per $\mathrm{h}$.

\section{Determination of brown adipose tissue type 2 deiodinase expression}

Dio 2 and $\beta$-actin mRNA expression was determined using a semi-quantitative RT-PCR. Total RNA was isolated using the TRIzol reagent (Invitrogen). Single-strand complementary DNA was synthesised using $20 \mu \mathrm{g}$ of total RNA using oligo $\mathrm{d}(\mathrm{T})$ as the primer. The reverse transcription product was amplified in $50 \mu \mathrm{l}$ of PCR buffer containing $10 \mathrm{pmol}$ of each oligonucleotide primer, $02 \mu \mathrm{m}$ of $\mathrm{dNTP}$ and one unit of DNA polymerase. The sequences of the oligonucleotides used were (s) act $\mathrm{cgg}$ tca ttc, tgc, tgc tca ag and (as) ttc aaa ggc tac ccc ata ag for Dio2 and (s) aca gag tac ttg cgc tca gga and (as) cca tca tga agt gtg acg ttg for $\beta$-actin. The samples were subjected to twenty-eight or forty cycles $(\beta$-actin and Dio2, respectively), consisting of $45 \mathrm{~s}$ at $95^{\circ} \mathrm{C}, 45 \mathrm{~s}$ at $55^{\circ} \mathrm{C}$ and $45 \mathrm{~s}$ at $72^{\circ} \mathrm{C}$. The last extension was carried out for 10 min. As a control, a reaction mixture containing an RNA sample with the appropriate primers, but without the RT, was included. The reaction products were analysed by $2 \%$ agarose gel electrophoresis, and the resulting bands were visualised by ethidium bromide staining. Band sizes were confirmed with a $1 \mathrm{~Kb}$ DNA ladder (Invitrogen). Relative changes in Dio2 expression were normalised to those in $\beta$-actin (housekeeping gene) expression. Polaroid pictures were taken; the pictures were digitised using a Hewlett Packard Scanner Jet 11CX (Hewlett-Packard Company), and the signals were analysed using an editing version of the NIH-ImageJ $14.7 \mathrm{~m}$ program.

\section{Determination of catecholamine content in brown adipose tissue}

Noradrenaline (NA), adrenaline and dopamine concentrations were determined according to the method of Villanueva et $a{ }^{(26)}$, using HPLC and an electrochemical detector (ESA Coulochem II). Briefly, BAT was homogenised $(1: 10, \mathrm{w} / \mathrm{v})$ in ice-cold 0.4 M-perchloric acid and centrifuged, and the supernatant was frozen until catecholamine content determination. Catecholamines were extracted by adsorption on acid-washed alumina at $\mathrm{pH} 8 \cdot 6$, washed with deionised water several times and eluted in a $0 \cdot 1 \mathrm{~m}$-perchloric acid solution.

\section{Statistical analysis}

All results are expressed as the means with standard errors. Data were analysed using Student's two-tailed $t$ test or twoway ANOVA with Tukey's post hoc test. Plasma TH levels, HD1 activity and BAT deiodinase expression evaluated in the cold exposure study were analysed using a two-way ANOVA with temperature and state of nutrition as factors. $P<0.05$ was considered to be statistically significant. Data were analysed with the Sigma Stat software version 3.5 (Systat Software, Inc.).

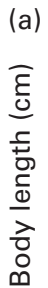

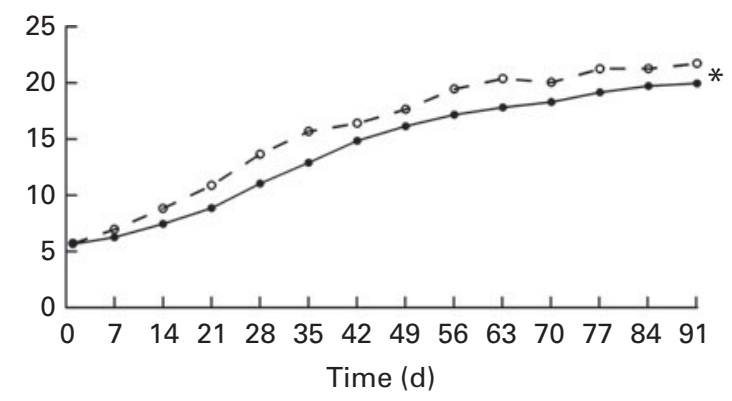

(b)

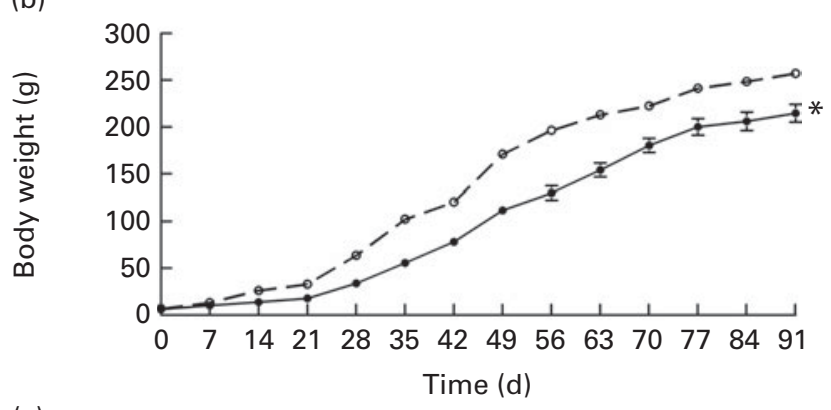

(c)

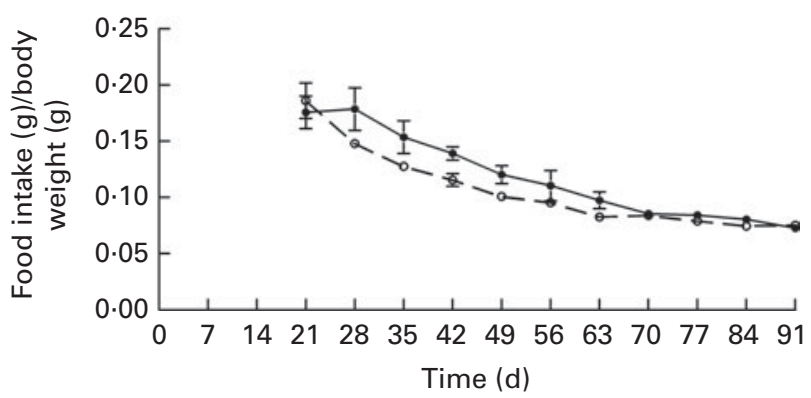

Fig. 1. (a) Body length, (b) body weight and (c) food intake/body weight in the female offspring of the control (-O-) or food-restricted dams during gestation and lactation (--). After day 21 , the offspring were fed ad libitum. Values are means, with their standard errors represented by vertical bars. ${ }^{*}$ Mean values were significantly different from those of the control group $(P<0.05$; two-way repeated-measures ANOVA). 
Table 1. Metabolic parameters in adult female offspring (postnatal day 90 ) of the control dams or restricted dams during gestation and lactation (Mean values with their standard errors of offspring of the control and restricted rat dams per group ( $n 5$ and $n 6$, respectively))

\begin{tabular}{|c|c|c|c|c|}
\hline \multirow[b]{2}{*}{ Parameters } & \multicolumn{2}{|c|}{ Control } & \multicolumn{2}{|c|}{ Restricted } \\
\hline & Mean & SEM & Mean & SEM \\
\hline \multicolumn{5}{|l|}{ Carcass components (\% BW) } \\
\hline Protein & $17 \cdot 87$ & 0.44 & $17 \cdot 88$ & 0.23 \\
\hline Fat & 9.84 & 0.59 & $7 \cdot 76^{\star}$ & 0.58 \\
\hline Retroperitoneal fat mass (\% BW) & 1.62 & 0.17 & $0.97^{\star \star}$ & 0.13 \\
\hline RMR $\left(\mathrm{kcal} / \mathrm{kg}^{0.75} \times \mathrm{h}\right)$ & $5 \cdot 78$ & 0.2 & $4 \cdot 48^{\star \star}$ & 0.1 \\
\hline 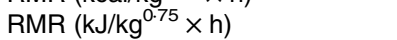 & $24 \cdot 18$ & 0.8 & $18 \cdot 74^{\star \star}$ & 0.4 \\
\hline Respiratory quotient & 0.74 & 0.01 & 0.75 & 0.01 \\
\hline
\end{tabular}

$\% \mathrm{BW}$, percentage of body weight.

Mean values were significantly different from those of the control group: ${ }^{*} P<0.05$, ${ }^{\star *} P<0.01$ (Student's $t$ test).

\section{Results}

The first consequences observed in the offspring of undernourished dams were changes in their body weight and length in comparison with the control group. Although both the groups of rats had the same body length, body weight of the restricted rats was significantly lower on the day of birth. These results are in agreement with the lower bodyweight gain observed in the restricted dams (88 (SEM 6.6) g) in comparison with the control dams (168 (sEm 3.7) g) during gestation. Although lower body weight and length (since day 7) were maintained in the restricted offspring at $90 \mathrm{~d}$ of age (Fig. 1), the slope in the growth rate was similar in both the groups. In addition, carcass protein contents were not different between the two groups, but relative lipid content (9.8 (SEM 0.6) v. 7.7 (SEM 0.6) \%, $P=0.035)$ and retroperitoneal fat content were significantly lower in the restricted offspring (Table 1). Since this metabolic phenotype showed no sex differences, subsequent analyses were carried out in the male or female offspring indistinctly.

\section{$R M R$}

The respiratory quotient - the relationship between $\mathrm{V}_{\mathrm{O} 2}$ and $\mathrm{CO}_{2}$ production - of the fasted rats showed similar values $(0 \cdot 75)$ in both the groups, but resting energy expenditure was significantly lower in the restricted rats $(24.18 v .18 .74 \mathrm{~kJ} /$ $\left.\mathrm{kg}^{0.75} \times \mathrm{h}\left(5.78 v .4 .48 \mathrm{kcal} / \mathrm{kg}^{0.75} \times \mathrm{h}\right), P<0.001\right)($ Table 1$)$

Day 21
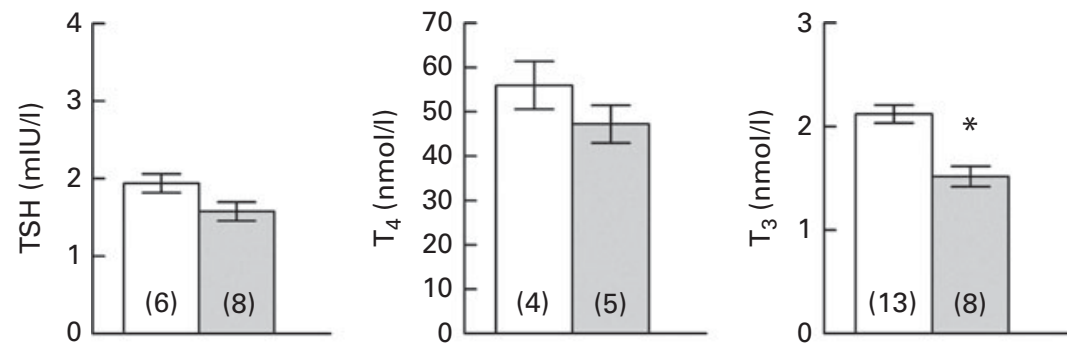

Day 90
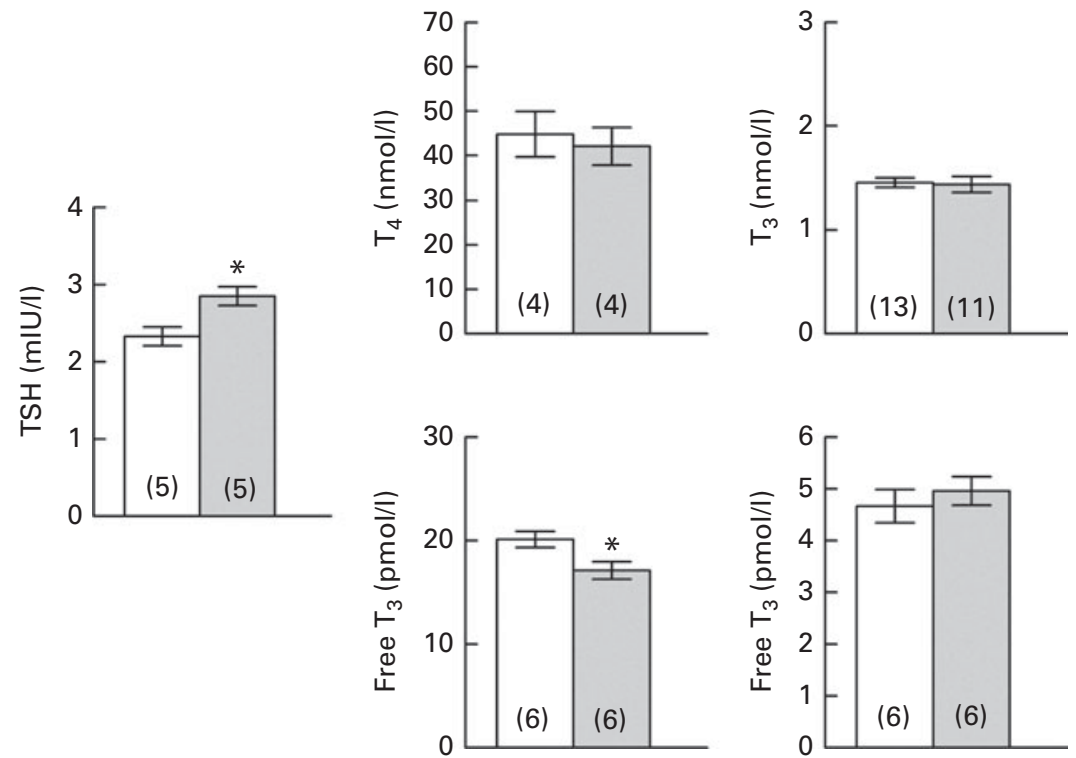

Fig. 2. Effects of undernutrition on plasma thyrotropin (TSH), thyroxine $\left(T_{4}\right)$ and $3,5,3^{\prime}$-triiodothyronine $\left(T_{3}\right)$ levels in the female offspring (postnatal day 21$)$ and free $T_{4}$ and free $T_{3}$ levels in adult rats (postnatal day 90 ). Values are means of the control ( $\square$ ) and $40 \%$ food-restricted ( $\square$ ) rats, with their standard errors represented by vertical bars. Numbers of rats per group are shown in parentheses. * Mean values were significantly different from those of the control group $(P<0.05 ;$ Student's $t$ test $)$. 

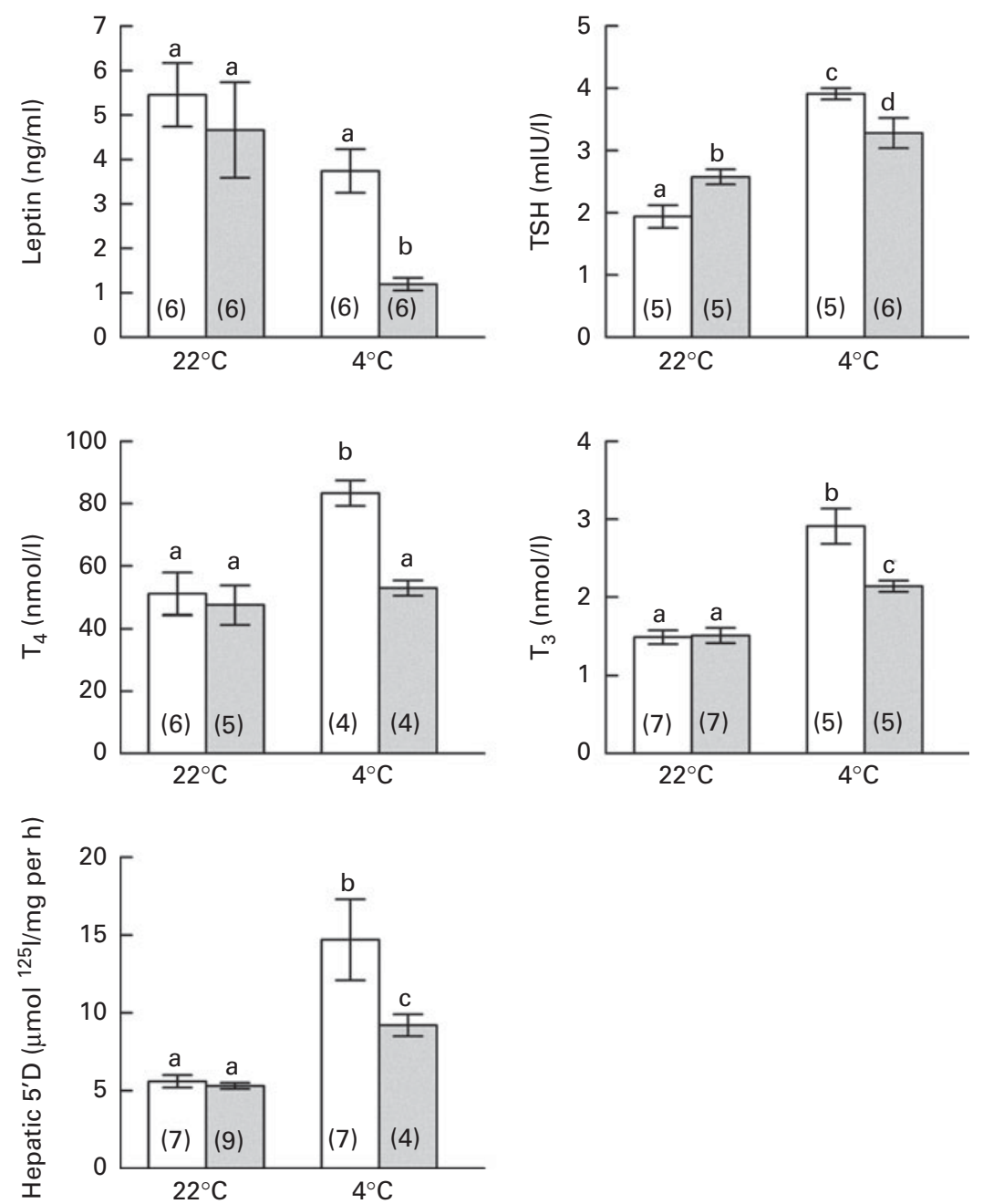

Fig. 3. Effects of perinatal undernutrition $\left(40 \%\right.$ food restricted) on leptin levels and thyroid response induced by cold exposure $\left(4 \pm 1{ }^{\circ} \mathrm{C}\right.$ for $\left.24 \mathrm{~h}\right)$ in adult male offspring (postnatal day 140). Values are means, with their standard errors represented by vertical bars. Numbers of rats per group are shown in parentheses. a,b,c,d Mean values with unlike letters were significantly different $\left(P<0.05\right.$; two-way ANOVA). $\square$, Control; $\square$, restricted; TSH, thyrotropin; $T_{4}$, thyroxine; $T_{3}, 3,5,3^{\prime}$ triiodothyronine; $5^{\prime} \mathrm{D}, 5^{\prime}$-deiodinase.

\section{Plasma thyroid hormone levels in the offspring}

Pups whose dams were restricted during gestation and lactation compared with those of the control dams exhibited no changes in $\mathrm{T}_{4}$ or TSH levels, but significantly lower $\mathrm{T}_{3}$ levels (28.5\%, $P<0.001)$ at weaning (postnatal day 21). In adulthood (postnatal day 90), the pattern of $\mathrm{T}_{3}$ and TSH levels was reversed, i.e. normal $\mathrm{T}_{3}$ and $\mathrm{T}_{4}$ levels with elevated concentrations of TSH were observed in the restricted rats $(22.1 \%$, $P<0.05$ ) (Fig. 2). To analyse the availability of TH, levels of free $\mathrm{T}_{3}$ and free $\mathrm{T}_{4}$ were measured on day 90. The restricted rats exhibited lower plasma free $\mathrm{T}_{4}$ levels in comparison with the control rats $(P=0.029)$, whereas both the groups exhibited no differences in plasma free $\mathrm{T}_{3}$ levels (Fig. 2).

\section{Cold exposure response}

As shown in Fig. 3, leptin levels were not different between the groups at room temperature, but a significant reduction in leptin levels was observed in the restricted rats during cold exposure. The control rats exhibited classical thyroid activation with increases in circulating TSH, $\mathrm{T}_{4}$ and $\mathrm{T}_{3}$ levels, as well as a rise in HD1 activity. Conversely, the restricted rats exhibited a partial and dissociated response, showing significant but attenuated increases in TSH and $\mathrm{T}_{3}$ levels and HD1 activity, but no changes in $\mathrm{T}_{4}$ levels.

BAT Dio2 is highly sensitive to sympathetic stimulation and is considered as a marker of sympathetic cold exposure response. At room temperature, the restricted rats exhibited the highest values of BAT Dio2 expression, suggesting an exacerbated sympathetic basal tone. When both the groups of rats were exposed to cold, only the control group exhibited a typical BAT Dio2 response to cold, with raised values similar to those observed in the restricted rats (Fig. 4). During cold exposure, the restricted rats also exhibited significantly high NA concentrations and a clear tendency of increasing BAT weight and dopamine and adrenaline concentrations (Table 2). 


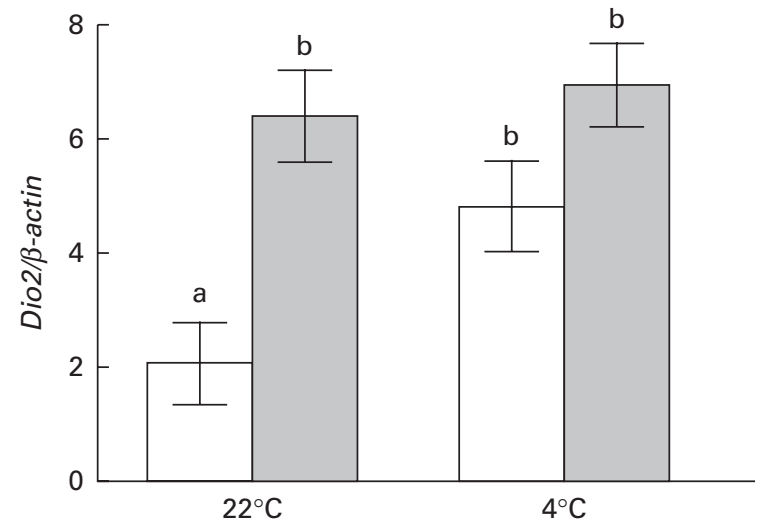

Fig. 4. Effects of perinatal undernutrition ( $40 \%$ food restricted) on Dio2 expression in the brown adipose tissue obtained from the male offspring (postnatal day 140) before and after being exposed to cold $\left(4 \pm 1^{\circ} \mathrm{C}\right.$ for $24 \mathrm{~h}$ ). Values are means ( $n 5$ rats per group), with their standard errors represented by vertical bars. Dio2 expression is normalised to $\beta$-actin expression. ${ }^{a, b}$ Mean values with unlike letters were significantly different $(P<0.001$; two-way ANOVA).

\section{Discussion}

In order to maintain a dynamic energy balance, food intake, thermogenesis and activities need to be regulated by systems that defend the stability of the energy reserves and body weight $^{(27)}$. Previous studies ${ }^{(28,29)}$ have shown that maternal undernutrition during both gestation and lactation produces the most drastic alteration in the body weight of pups. In the present study, a $40 \%$ maternal food restriction during gestation and lactation in rats induced perinatal growth retardation with lower birth weight and smaller body size and lower body weight until adulthood, confirming the results obtained under similar conditions by Holemans et al. ${ }^{(30,31)}$ and Miñana-Solis \& Escobar ${ }^{(32)}$. Undernourished rats fed ad libitum after weaning ingested less food, accumulated fewer lipids and maintained a lower RMR as adults. When we correlated food intake with these factors, only body weight exhibited a significant association, whereas fat deposits and RMR remained as lowered altered variables. The absence of catch-up growth has been described previously by Garofano et al. ${ }^{(33)}$ and Holemans et al. ${ }^{(31)}$, who also showed that perinatal food restriction is accompanied by normal

Table 2. Effects of perinatal undernutrition ( $40 \%$ food restricted) on weight and catecholamine content in the brown adipose tissue (BAT) obtained from the male offspring (postnatal day 140) before and after being exposed to cold $\left(4 \pm 1^{\circ} \mathrm{C}\right.$ for $\left.24 \mathrm{~h}\right)$

(Mean values with their standard errors)

\begin{tabular}{lcccccc}
\hline & \multicolumn{2}{c}{ Control } & & \multicolumn{2}{c}{ Restricted } \\
\cline { 2 - 3 } \cline { 6 - 7 } & Mean & SEM & & Mean & SEM \\
\hline BAT weight (\% BW) & 0.08 & 0.018 & & 0.11 & 0.015 \\
Adrenaline (ng/g tissue) & 16.3 & 2.2 & & 23.6 & 4.3 \\
Noradrenaline (ng/g tissue) & 313.8 & 35.5 & & $527.0^{*}$ & 32.5 \\
Dopamine (ng/g tissue) & 8.3 & 2.9 & & 15.2 & 4.8 \\
\hline
\end{tabular}

$\%$ BW, percentage of body weight.

${ }^{*}$ Mean value was significantly different from that of the control group $(P<0.01$; Student's $t$ test). values of heart rate, blood pressure, plasma TAG, cholesterol and glycaemia, suggesting that delayed catch-up growth has protective effects on metabolism and prevents adult obesity ${ }^{(29)}$.

All our findings support the idea that these neonatal periods are crucial windows in the development of adipose depots ${ }^{(34)}$ and predetermine RMR limits. Recent publications have addressed sex-related differences observed in neonatal nutrient restriction studies and their results are widely discordant, showing the highest sensitivity in females ${ }^{(35)}$ than in males ${ }^{(36)}$ or a similar sensitivity in both sexes. Nevertheless, in all these studies, it is clear that protein restriction during development results in a global metabolic readjustment. This readjustment is called metabolic programming and has been implicated in the predisposition to developing metabolic illnesses such as obesity, non-insulin-dependent diabetes and hypertension $^{(3)}$. Although a limitation of the present study is that we did not perform all the measurements in male and female rats, we found that the persistent increase in TSH levels and the programming of the thyroid axis occur in both the sexes.

Extensive literature has demonstrated the crucial role of TH in the development and function of several tissues, besides in those of the brain. In metabolic terms, TH are crucial for maintaining RMR and obligatory thermogenesis and play an important role in facultative thermogenesis by exerting a synergic effect with catecholamine in BAT, promoting heat production in a cold environment ${ }^{(9)}$ and decreasing metabolic efficiency to control body weight during overfeeding ${ }^{(10)}$. Moreover, TH are critical for stimulating lipogenesis and maintaining fat depots in adulthood ${ }^{(37)}$. In addition, a significant reduction in fat mass has been observed in perinatal hypothyroid animals, which tend to be leaner with reduced retroperitoneal fat depot and adipocyte volume ${ }^{(38)}$. Although there are studies that have demonstrated that energy balance can be programmed by prenatal and neonatal food restriction $^{(39)}$, the effect of this disruption upon the thyroid system has not been explored completely. In the present experiment, the offspring of undernourished dams exhibited lower $\mathrm{T}_{3}$ levels with normal plasma $\mathrm{T}_{4}$ and $\mathrm{TSH}$ levels at weaning, but on postnatal day 90 and maybe for the rest of their lives (the remaining $140 \mathrm{~d}$ ), apparent normal $\mathrm{T}_{3}$ and $\mathrm{T}_{4}$ levels were accompanied by significantly lower levels of free $\mathrm{T}_{4}$ and persistently higher levels of TSH, thus providing evidence that perinatal undernutrition might induce functional changes in the thyroid gland.

Normally, binding of TSH to the TSH receptor (TSHR) stimulates both growth and function of thyroid cells, promoting cell proliferation ${ }^{(40,41)}$ and $\mathrm{TH}$ production ${ }^{(42)}$. With regard to metabolic disorders, in recent years, TSHR have been identified in a number of tissues including the brain, testes, kidney, heart, bone, thymus, lymphocytes, adipose tissue and fibroblasts, suggesting that TSH may have a wider functional role than is traditionally recognised ${ }^{(43)}$. In normal and hypothyroid conditions, TSH exhibits lipolytic and thermogenic effects in white adipose tissue and BAT, respectively, during the postnatal period ${ }^{(44-46)}$. Studies showing whether these adipose tissue TSH sensitivities are modified by a neonatal foodrestricted regimen have not been documented, but could 
explain in part the present results, showing that although $\mathrm{TH}\left(\mathrm{T}_{4}\right.$ and $\mathrm{T}_{3}$ ) levels are normal, the white adipose depot is scarce, whereas BAT sympathetic tone is exacerbated (BAT Dio2).

Another objective of the present study was to determine the functional integrity of the HPT axis of food-restricted animals on postnatal day 140 . The moderate pituitary response to release TSH in a cold environment with a preferred formation/secretion of $\mathrm{T}_{3}$ over $\mathrm{T}_{4}$, as well as discrete increases in HD1 activity, is accompanied by the maintenance of an exacerbated sympathetic BAT response (a significant increase in NA concentrations) and suggests the existence of a state resembling subclinical hypothyroidism in these animals ${ }^{(47)}$. Thermogenesis is mainly controlled in a synergistic way by sympathetic NA release and local $\mathrm{T}_{3}$ generation (Dio2 activity) in the BAT of small mammals ${ }^{(9)}$. The BAT response to both signals is due to an increase in the synthesis of uncoupling protein 1, which allows protons to leak into the mitochondrial matrix, reducing ATP synthesis, and, as a consequence, energy is lost as heat (for a review, see Harper \& Seifert ${ }^{(48)}$ ). It is well known that thyroid dysfunctions are accompanied by opposite alterations in sympathetic nervous system responses. Cvijic et al. ${ }^{(49)}$ have reported increased serum dopamine- $\beta$-hydroxylase and BAT monoamine oxidase levels in thyroidectomised rats in response to a cold environment. Higher plasma NA levels have been reported in hypothyroid subjects ${ }^{(50)}$. Moreover, it has been shown that in rats under intrauterine food restriction, thermoregulation during cold acclimatisation is altered in the offspring on postnatal day $90^{(51)}$. On the other hand, recent studies have reported that TSHR-deficient hyt/hyt mice become hypothermic in cold conditions despite $\mathrm{T}_{4}$ administration. Transfection of TSHR into the BAT of these mice resulted in a marked improvement in core temperature, leading to the conclusion that both functional TSHR and adequate free TH are required for normal temperature regulation ${ }^{(45)}$. Association of TSHR with sympathetic activation in BAT has not been documented, but studies on THSR in thermogenesis have demonstrated that TSH/TSHR activation is accompanied by an increase in cyclic AMP content in BAT, suggesting that the stimulated uncoupling protein 1 expression is mediated via cyclic AMP response element $(\mathrm{CRE})^{(45)}$.

The stimulus produced by cold environment exposure is conducted by adrenergic neurons from the medulla, which projects its afferents to the hypothalamic paraventricular nucleus, where the TRH-releasing neurons are stimulated ${ }^{(52)}$. It has been suggested that catecholamines released by this pathway increase the set point for negative feedback regulation of TRH gene expression by $\mathrm{T}_{3}$ through adrenaline-stimulated cyclic AMP response element binding protein (CREB) phosphorylation, which activates the TRH promoter, thus increasing TRH release in the median eminence, and subsequently activates the thyroid axis. Additionally, leptin in the arcuate nucleus inhibits the production of neuropeptide $\mathrm{Y}$, which is a potent transcription inhibitor of the TRH gene in the paraventricular nucleus ${ }^{(52,53)}$. Leptin levels were lower in the perinatal restricted rats in adulthood during cold exposure, suggesting that neuropeptide $\mathrm{Y}$ production in the arcuate nucleus is less inhibited and partially antagonises the adrenergic stimulatory effect reducing the paraventricular nucleus release of TRH and, as a consequence, lowers TSH and $\mathrm{TH}$ production. On the other hand, the increased TSH levels that we found in the restricted rats in basal conditions are controversial. In the pituitary gland, brain and BAT, there is additional $\mathrm{T}_{3}$ generation by Dio2-catalysed $\mathrm{T}_{4}$ deiodination. In the feedback regulation of TSH, this mechanism correlates better with plasma $\mathrm{T}_{4}$ or $\mathrm{T}_{3}$ produced locally by Dio2 activity than with plasma $T_{3}$. Interestingly, a lower RMR is correlated with lower free $\mathrm{T}_{4}$ and higher TSH levels and not with serum $\mathrm{T}_{3}$ levels ${ }^{(54)}$. In recent years, Dutra et al. ${ }^{(55)}$ have found that adult rat offspring whose mothers were protein restricted during lactation show some aspects of hyperthyroidism with increased serum $\mathrm{T}_{3}$ and higher leptin levels at weaning, suggesting that leptin could contribute to higher plasma $\mathrm{T}_{3}$ levels by an enhanced HD1 activity. In the same model, they also found a lower in vitro TSH-releasing response to TRH, lower plasma TSH levels and a higher pituitary Dio2 activity, indicating that higher $\mathrm{T}_{3}$ local generation lowers TSH production and plasma levels ${ }^{(19)}$. We hypothesise that in the present study in the offspring of energy-restricted rat dams throughout gestation and lactation, in contrast to that observed in dams protein restricted during lactation, the lower plasma free $T_{4}$ levels reduce $T_{3}$ production in the pituitary and the hypothalamus and the $\mathrm{T}_{3}$ feedback mechanism causes an increase in plasma TSH levels.

Persistent increases in plasma TSH levels have been described in the so-called subclinical hypothyroidism, which exhibits a world prevalence between 3 and $8 \%$ and is correlated with lipid abnormalities, principally dyslipidaemia and, in some cases, insulin resistance and cardiac failure ${ }^{(42,56,57)}$. Although the origin of this syndrome has not been elucidated, an epidemiological analysis has pointed out that women who develop spontaneous hypothyroidism in adulthood are characterised by low birth weight and short length at birth, short height during early childhood and low RMR during late childhood. Moreover, many of these women exhibited previous subclinical hypothyroidism and positive thyroperoxidase antibodies, suggesting that spontaneous hypothyroidism must be included among those adult disorders whose development is initiated during early life $\mathrm{e}^{(20)}$.

Further studies are needed to clarify the role of persistently higher TSH levels in the development and function of adipose tissue and other organs, but the present data suggest that perinatal undernutrition programmes permanent alterations in both thyroid function and HPT axis, which could be implicated in the predisposition to developing metabolic illnesses associated with perinatal undernutrition.

\section{Acknowledgements}

The authors are grateful to Guadalupe Delgado for technical assistance and Marcela Sánchez for proofreading in the preparation of the article. L. Q. is a fellow of Comisión de Operación y Fomento de Actividades Académicas-IPN. The present study was supported by the Instituto Politécnico Nacional (SIP 20110605). L. Q. designed and implemented the study with assistance from R. A.-M., C. A. and R. R.; 
B. A. conducted the experiment to determine HD1 activity. L. Q. wrote the first draft of the manuscript with assistance from C. A., R. A.-M. and B. A. The authors declare that there is no conflict of interest that could be perceived as prejudicing the impartiality of the research reported.

\section{References}

1. Hales CN \& Barker DJ (2001) The thrifty phenotype hypothesis. Br Med Bull 60, 5-20.

2. Vickers MH, Breier BH, Cutfield WS, et al. (2000) Fetal origins of hyperphagia, obesity, and hypertension and postnatal amplification by hypercaloric nutrition. $\mathrm{Am} J$ Physiol Endocrinol Metab 279, E83-E87.

3. Reynolds RM, Walker BR, Phillips DI, et al. (2009) Programming of hypertension. Associations of plasma aldosterone in adult men and women with birth weight, cortisol, and blood pressure. Hypertension 53, 932-936.

4. Lucas A (1994) Role of nutritional programming in determining adult morbidity. Arch Dis Child 71, 288-290.

5. Vieau D (2011) Perinatal nutritional programming of health and metabolic adult disease. World J Diabetes 2 , 133-136.

6. Fowden AL, Giussani DA \& Forhead AJ (2006) Intrauterine programming of physiological systems: causes and consequences. Physiology 21, 29-37.

7. Pracyk JB, Seidler FJ, McCook EC, et al. (1992) Pituitary-thyroid axis reactivity to hyper- and hypothyroidism in the perinatal period: ontogeny of regulation and long-term programming of responses. J Dev Physiol 18, $105-109$.

8. Brown RS, Shalhoub V, Coulter S, et al. (2000) Developmental regulation of thyrotropin receptor gene expression in the fetal and neonatal rat thyroid: relation to thyroid morphology and to thyroid-specific gene expression. Endocrinology 141, 340-345.

9. Silva JE (2011) Physiological importance and control of nonshivering facultative thermogenesis. Front Biosci (Schol ed) 3, 352-371.

10. Cannon B \& Nedergaard J (2004) Brown adipose tissue: function and physiological significance. Physiol Rev 84, 277-359.

11. LoPresti JS, Gray D \& Nicoloff JT (1991) Influence of fasting and refeeding on $3,3^{\prime}, 5^{\prime}$-triiodothyronine metabolism in man. J Clinl Endocrinol Metab 72, 130-136.

12. Quigley K, Goya R, Nachreiner R, et al. (1990) Effects of underfeeding and refeeding on $\mathrm{GH}$ and thyroid hormone secretion in young, middle-age, and old rats. Exp Gerontol 25, 447-457.

13. van Haasteren GA, Linkels E, van Toor H, et al. (1996) Effects of long-term food reduction on the hypothalamus-pituitary-thyroid axis in male and female rats. J Endocrinol 150, 169-178.

14. Aláez C, Calvo R, Obregón MJ, et al. (1992) Thyroid hormones and 5'-deiodinase activity in neonatal undernourished rats. Endocrinology 130, 773-779.

15. Oberkotter LV \& Rasmussen K (1992) Changes in plasma thyroid hormone concentrations in chronically foodrestricted female rats and their offspring during suckling. J Nutr 122, 435-441.

16. Fetoui H, Bouaziz H, Mahjoubi-Samet A, et al. (2006) Food restriction-induced thyroid changes and their reversal after refeeding in female rats and their pups. Acta Biol Hung 57, 391-402.
17. Passos MCF, Fonte Ramos C, Dutra SCP, et al. (2002) Longterm effects of malnutrition during lactation on the thyroid function of offspring. Horm Metab Res 34, 40-43.

18. Wilcoxon JS \& Redei E (2004) Prenatal programming of adult thyroid function by alcohol and thyroid hormones. Am J Physiol Endocrinol Metab 287, E318-E326.

19. Lisboa PC, Fagundes AT, Denolato AT, et al. (2008) Neonatal low-protein diet changes deiodinase activities and pituitary TSH response to TRH in adult rats. Exp Biol Med 233, 57-63.

20. Kajantie E, Phillips WDI, Osmond C, et al. (2006) Spontaneous hypothyroidism in adult women is predicted by small body size at birth and during childhood. J Clinl Endocrinol Metab 91, 4953-4956.

21. Phillips DI, Osmond C, Baird J, et al. (2002) Is birth weight associated with thyroid autoimmunity? A study in twins. Thyroid 12, 377-380.

22. Obregón MJ, Ruiz de Oña C, Calvo R, et al. (1991) Outer ring iodothyronine deiodinases and thyroid hormone economy: responses to iodine deficiency in the rat fetus and neonate. Endocrinology 129, 2663-2673.

23. Ayala MR, Racotta R, Hernández-Montes H, et al. (2006) Some metabolic effects on lactating rats of a low-energy diet restricted in good-quality protein. Br J Nutr 96, 667-673.

24. Valverde C \& Aceves C (1989) Circulating thyronines and peripheral monodeiodination in lactating rats. Endocrinology 124, 1340-1344.

25. Aceves C, Escobar C, Rojas-Huidobro R, et al. (2003) Liver $5^{\prime}$-deiodinase activity is modified in rats under restricted feeding schedules: evidence for post-translational regulation. $J$ Endocrinol 179, 91-96.

26. Villanueva I, Piñón M, Quevedo-Corona L, et al. (2002) Chemical sympathectomy alters food intake and thermogenic responses to catecholamines in rats. Life Sci $\mathbf{7 1}$, 789-801.

27. Remmers F \& Delemarre-van de Waal HA (2011) Developmental programming of energy balance and its hypothalamic regulation. Endocr Rev 32, 272-311.

28. Léonhardt M, Lesage J, Croix D, et al. (2003) Effects of perinatal maternal food restriction on pituitary-gonadal axis and plasma leptin level in rat pup at birth and weaning and on timing of puberty. Biol Reprod 68, 390-400.

29. Howie GJ, Sloboda DM \& Vickers MH (2012) Maternal undernutrition during critical windows of development results in differential and sex-specific effects on postnatal adiposity and related metabolic profiles in adult rat offspring. Br J Nutr 108, 298-307.

30. Holemans K, Van Bree R, Verhaeghe J, et al. (1997) Maternal semistarvation and streptozotocin-diabetes in rats have different effects on the in vivo glucose uptake by peripheral tissues in their female adult offspring. $J$ Nutr 127, $1371-1376$.

31. Holemans K, Gerber R, Meurrens K, et al. (1999) Maternal food restriction in the second half of pregnancy affects vascular function but not blood pressure of rat female offspring. Br J Nutr 81, 73-79.

32. Miñana-Solis MC \& Escobar C (2007) Increased susceptibility to metabolic alterations in young adult females exposed to early malnutrition. Int J Biol Sci 3, 12-19.

33. Garofano A, Czernichow P \& Breant B (1998) Postnatal somatic growth and insulin contents in moderate or severe intrauterine growth retardation in the rat. Biol Neonate $\mathbf{7 3}$, 89-98.

34. Muhlhausler B \& Smith SR (2009) Early-life origins of metabolic dysfunction: role of the adipocyte. Trends Endocrinol Metab 20, 51-57. 
35. Zambrano E, Bautista CJ, Deás M, et al. (2006) A low maternal protein diet during pregnancy and lactation has sex- and window of exposure-specific effects on offspring growth and food intake, glucose metabolism and serum leptin in the rat. $J$ Physiol 571, 221-230.

36. Sugden MC \& Holness MJ (2002) Gender-specific programming of insulin secretion and action. J Endocrinol 175, $757-767$.

37. Oppenheimer HJ, Schwartz LH, Lane TJ, et al. (1991) Functional relationship of thyroid hormone-induced lipogenesis, lipolysis, and thermogenesis in the rat. J Clin Invest $\mathbf{8 7}$, $125-132$.

38. Curcio C, Lopes AM, Ribeiro MO, et al. (1999) Development of compensatory thermogenesis in response to overfeeding in hypothyroid rats. Endocrinology 140, 3438-3443.

39. Remmers F, Fodor M \& Delemarre-van de Waal HA (2008) Neonatal food restriction permanently alters rat body dimensions and energy intake. Physiol Behav 95, 208-215.

40. Medina DL \& Santisteban P (2000) Thyrotropin-dependent proliferation of in vitro rat thyroid cell systems. Eur J Endocrinol 143, 161-178.

41. Kimura T, Dumont JE, Fusco A, et al. (1999) Insulin and TSH promote growth size of PC C13 rat thyroid cells, possibly via a pathway different from DNA synthesis: comparison with FRTL-5 cells. Eur J Endocrinol 140, 94-103.

42. De Felice M, Postiglione MP \& Di Lauro R (2004) Minireview: thyrotropin receptor signaling in development and differentiation of the thyroid gland: insights from mouse models and human diseases. Endocrinology 145, 4062-4067.

43. Davies T, Marians R \& Latif R (2002) The TSH receptor reveals itself. J Clin Invest 110, 161-164.

44. de Lloyd A, Bursell J, Gregory JW, et al. (2010) TSH receptor activation and body composition. J Endocrinol 204, 13-20.

45. Endo T \& Kobayashi T (2008) Thyroid-stimulating hormone receptor in brown adipose tissue is involved in the regulation of thermogenesis. Am J Physiol Endocrinol Metab 295, E514-E518.

46. Endo T \& Kobayashi T (2012) Expression of functional TSH receptor in white adipose tissues of hyt/hyt mice induces lipolysis in vivo. Am J Physiol Endocrinol Metab 302, E1569-E1575.

47. Ross DS (2000) Subclinical hypothyroidism. In Werner and Ingbar's. The Thyroid. A Fundamental and Clinical Text, 9th ed., pp. 1001-1006 [LE Braverman and RD Utiger, editors]. Philadelphia, PA: Lippincott Williams and Wilkins.

48. Harper ME \& Seifert EL (2008) Thyroid hormone effects on mitochondrial energetics. Thyroid 18, 145-156.

49. Cvijic G, Petrovic N, Djordjevic J, et al. (2004) Effect of cold exposure on serum DBH and interscapular brown adipose tissue MAO activity in hypothyroid $\mathrm{T}_{3^{-}}$and $\mathrm{T}_{4}$-treated rats. Ann N Y Acad Sci 1018, 214-218.

50. Coulombe P, Dussalult JH \& Walker P (1976) Plasma catecholamine concentrations in hyperthyroidism and hypothyroidism. Metabolism 25, 973-979.

51. Luz J, Griggio MA \& Vieira LV (2003) Impact of maternal food restriction on cold-induced thermogenesis in the offspring. Biol Neonate 84, 252-258.

52. Fekete C \& Lechan RM (2007) Negative feedback regulation of hypophysiotropic thyrotropin-releasing hormone (TRH) synthesizing neurons; role of neuronal afferents and type 2 deiodinase. Front Neuroendocrinol 28, 97-114.

53. Chiamolera MI \& Wondisford FE (2009) Minireview: thyrotropin-releasing hormone and the thyroid hormone feedback mechanism. Endocrinology 150, 1091-1096.

54. Bianco AC, Salvatore D, Gereben B, et al. (2002) Biochemistry, cellular and molecular biology, and physiological roles of the iodothyronine selenodeiodinases. Endocr Rev 23, 38-89.

55. Dutra SCP, Passos MCF, Lisboa PC, et al. (2003) Liver deiodinase activity is increased in adult rats whose mothers were submitted to malnutrition during lactation. Horm Metab Res 35, 268-270.

56. Biondi B \& Cooper DS (2008) The clinical significance of subclinical thyroid dysfunction. Endocr Rev 29, 76-131.

57. Ruhla S, Weickert MO, Arafat A, et al. (2010) A high normal TSH is associated with the metabolic syndrome. Clin Endocrinol 72, 696-701. 